\title{
Surgical Education and Training in the US: a Collaborative Effort to Deliver the Next Generation of Surgeons
}

\author{
Hope T. Jackson ${ }^{1} \cdot$ Khashayar Vaziri $^{1} \cdot$ Barbara Lee Bass $^{1}$ (D)
}

Received: 29 July 2021 / Accepted: 14 August 2021/Published online: 20 August 2021

(c) Association of Surgeons of India 2021

\begin{abstract}
The foundational principles of surgical training in the USA are based on didactic education, structured skill training, and experiential learning in surgical patient care with the supervision of surgical faculty. A consortium of professional organizations, academic institutions, and teaching hospitals with surgical faculty provide the structural framework, policies, and curriculum to train and evaluate surgeons capable of independent practice. This manuscript describes the roles of the organizations responsible for surgical training in the USA and highlights areas in evolution in the modern surgical education landscape.
\end{abstract}

Keywords Surgical education · Surgical training · American Board of Surgery · Accreditation Council for Graduate Medical Education · American College of Surgeons

\section{Introduction}

The foundational principles of surgical training in the USA can be traced back to the early years of the twentieth century when Dr. William Halsted, the first surgeon-in-chief at Johns Hopkins Hospital, sought to change the then practiced apprenticeship model of surgical training. Dr. Halsted was dissatisfied with the varying nature of apprenticeships in terms of length, supervision, structure, and assessment of competency [1]. His novel training model consisted of a defined period of training time in residence at the teaching hospital, with supervision and graded autonomy of the residents and final assessment of competence prior to advancing the young surgeons to independent practice [1].

While the Halstedian principles remain foundational in US surgical training, the field of surgery and surgical education has evolved dramatically over these last 120 years in response to the dynamic changes in surgical procedural complexity, introduction of new technologies, and implementation of new training structures and process. The current operating structure was developed to support the ultimate

Barbara Lee Bass

bbass@gwu.edu

1 The George Washington University School of Medicine and Health Sciences, George Washington University, 2300 I Street, NW, Washington, DC, USA goal of surgical training - creating a professional surgical workforce that can adequately serve the needs of the US population.

Unlike many nations around the globe where a single College of Surgeons holds responsibility for this comprehensive process, in the USA, this goal is achieved with the collaboration of delegated authority regulatory organizations, professional societies, teaching institutions, and dedicated teaching faculty. This collaboration creates surgical training programs charged to focus on didactic and experiential education with graduated responsibility and an ultimate goal of autonomy in patient care.

Accredited US surgical training programs, known as residency programs, are established in accredited hospitals. Successful graduates of these highly structured training programs are then eligible to enter the examination process to become a board-certified surgeon.

Institutional and training programs requirements are established and verified by the Accreditation Council for Graduate Medical Education. The second step, the individual certification of a resident who has completed an accredited training program, is overseen by the member Boards of the American Board of Medical Specialties. This two party, linked but separate, structure has been developed to ensure high-quality training programs are in fact delivering well trained surgeons to the certification process and then into surgical practice in the USA. 
This manuscript will review the structure of surgical training in the USA with focus on the regulatory structure, the roles of surgical professional societies, and the new areas that are framing current changes in surgical education and training. While general surgery training programs will be the focus of our discussion, many of the surgical specialties in the USA that have derived from general surgery (i.e., Vascular, Cardiac, Plastics, etc.) have adopted and rely on the same principles, structures, and processes, as do other surgical specialties such as Neurological Surgery, Head and Neck-Otolaryngology, Ophthalmology, and others.

\section{How Are Surgical Training Programs Accredited and Regulated in the USA?}

\section{The Accreditation Council for Graduate Medical Education}

ACGME is a private not-for-profit organization that establishes and maintains the standards for graduate medical education in all medical and surgical disciplines the USA. The US federal and state governments do not regulate the number or quality of healthcare-related training programs in the USA; this responsibility is delegated to the professional regulatory agency of the ACGME.

The ACGME sets standards for residency programs, fellowship programs, and sponsoring institutions. "The mission of the ACGME is to improve health care and population health by assessing and enhancing the quality of resident and fellow physicians' education through advancements in accreditation and education" [2]. While ACGME accreditation is a voluntary process and one that is pursued only by institutions with the financial and structural means to support a training program, only graduates of ACGME accredited programs will be eligible to enter the Board certification process - essentially rendering ACGME accreditation an essential requirement for a surgical and all other graduate medical education training programs in the USA.
Accreditation and ongoing compliance are supervised by review committees. Residency programs are overseen by the Residency Review Committee (RRC), fellowships by the Fellowship Review Committee, and institutions by an Institutional Review Committee. As of 2019, 865 institutions were ACGME accredited sponsoring 12,000 residency and fellowship training programs in 182 specialties [3]. The members of the RRC committees are practicing surgeons who are actively engaged as faculty and program directors of residency and fellowship programs. These members provide voluntary service to oversee and review programs and to review and advance standards for program and institutional accreditation requirements.

\section{Residency and Fellowship Programs}

In order to achieve ACGME accreditation, each residency or fellowship training program must comply with Common Program Requirements and Specialty Specific Program Requirements. Common Program Requirements are a set of standards that apply to all training programs regardless of specialty, while Specialty Specific Program Requirements provide specific standards for training in each specialty (i.e., General Surgery Program Requirements).

\section{Common Program Requirements}

The Common Program Requirements establish standards for the clinical learning environment in order for residents and fellows to train and develop the knowledge and skills needed to eventually assume independent patient care. The purpose of these standards is to facilitate an environment where trainees can participate in the care of patients under the supervision of qualified faculty members. The key elements of the Common Program Requirements are illustrated in Table 1, and are briefly summarized below [4].

Table 1 ACGME Common Program Requirements

\begin{tabular}{|c|c|}
\hline Common Program Requirement & Description \\
\hline Oversight & $\begin{array}{l}\text { Delineates the oversight and structure of the program ensuring adequate resources and appropriate learn- } \\
\text { ing environment }\end{array}$ \\
\hline Personnel & Establishes the roles of Program Director, Faculty, and Program Coordinator \\
\hline Resident Appointments & Establishes eligibility requirements for initial appointment or transfer \\
\hline Educational Program & Delineates educational content and structure in accordance with ACGME Core Competencies \\
\hline Evaluation & $\begin{array}{l}\text { Requires formative and summative evaluation of trainees, faculty and program. Establishes Clinical } \\
\text { Competency Committee and Program Evaluation Committee }\end{array}$ \\
\hline Learning and Working Environment & Sets standards for safety, work hour regulations, transitions of care and quality improvement \\
\hline
\end{tabular}




\section{Oversight}

The majority of training programs involve multiple hospitals and clinical training sites. All training programs have a primary sponsoring institution that has ultimate academic and financial responsibility for all of the trainees. The sponsoring institution must be an ACGME accredited institution and all participating sites must have a formal agreement with the sponsoring institution. The program in conjunction with the sponsoring institution and the participating sites must provide adequate resources and ensure an appropriate learning environment for the trainees.

\section{Personnel}

This requirement defines the role of the Program Director, faculty, and Program Coordinator. The Program Director is an appointed faculty member who is ultimately accountable for compliance with all of the common and specialty specific program requirements. The qualifications, responsibilities, and overall authority of the program director are delineated in this requirement. Similarly, the qualifications, responsibilities, and expectations of the faculty are also characterized. Finally, the role of the Program Coordinator is established as a member of the leadership team with specific attention to the need for leadership and personnel management skills.

\section{Resident Appointments}

The eligibility requirements for initial appointment or transfer to an ACGME accredited training program are established and detailed in this section of the common program requirements. This sets standards for eligibility and requisite verification of previous training for applicants from the USA and abroad. Currently, eligibility for training in ACGME accredited US surgery residency programs is restricted to graduates of LCME accredited medical schools, or graduates from osteopathic medical school accredited by the American Osteopathic Association Commission on Osteopathic College Accreditation (AOACOCA). Graduates from medical schools outside of the USA or Canada must either hold a current valid certificate from the Educational Commission for Foreign Medical Graduates (ECFMG), or hold a full unrestricted medical license in the jurisdiction of the ACGME accredited institution. ECFMG certification requires successful completion of the USMLE Step I and Step II examinations.

\section{Educational Programs}

The educational curriculum must contain competency-based goals in accordance with the mission of the sponsoring institution and aim to fulfill the needs of the community it serves with the ultimate goal of preparing its trainees for autonomous practice. The ACGME provides a conceptual framework of Core Competencies required for a physician to achieve autonomous practice. The six domains of the ACGME Core Competencies are medical knowledge, patient care, system-based practice, practice-based learning, professionalism, and interpersonal communication skills. The educational content and structure of a program must align with these ACGME Core Competencies, and the assessment of individual trainees in each of these core competencies must be benchmarked using the ACGME Specialty Specific Milestones.

\section{Evaluation}

Feedback and evaluation are key components of any training program. This requirement establishes the need for formative and summative evaluation of the trainees, faculty, and program as a whole. A program must have a Clinical Competency Committee (CCC) that reviews all resident evaluations at least twice per year. The CCC determines each trainee's progress on specialty specific Milestones, and provides the program director with recommendations on individual resident progress. A program must also have a Program Evaluation Committee (PEC) with the primary responsibility to perform an annual program evaluation. This evaluation includes an assessment of progress towards program goals, development of new goals, and alignment with overall program aims.

\section{The Learning and Working Environment}

A safe and healthy learning and working environment committed to excellence in quality of care while ensuring the well-being of the health care team is the goal of this requirement. This requirement delineates the standards for education on safety, quality improvement, supervision, accountability, and work hour regulations. The work hour regulations for all trainees are limited to no greater than $80 \mathrm{~h}$ per week, no greater than a 24-h continuous shift, and no more frequent than every third night call. In addition to work-hour regulations, this standard also delineates requirements for education in fatigue mitigation, and safe transitions of care.

\section{Specialty Specific Requirements}

Specialty Specific Requirements mirror Common Program Requirements with respect to the key elements of oversight, personnel, resident appointments, educational program, evaluation, and the learning and working environment. However, specialty specific requirements provide more detail and guidance on implementation of these requirements within the specialty training program. The ACGME Program 
Requirements in General Surgery provide more specific requirements in the educational program and evaluation [5].

\section{Educational Program}

The General Surgery Program Requirements delineate specific curriculum components required for training. The overall educational program is structured in accordance with the conceptual framework of the ACGME Core Competencies; however, the program requirements are much more specific with regard to the clinical exposure and experiences in General Surgery and its subspecialties such as Vascular Surgery, Colorectal Surgery, Trauma Critical Care, Surgical Oncology, Transplant, and Thoracic Surgery. In addition to the requirements of clinical experiences, the General Surgery Program Requirements establish operative case requirements. Every trainee is required to submit an operative log of all procedures performed during their training. There is a minimum requirement of 250 cases at the end of the second year of postgraduate training, and a minimum of 850 cases at the completion of training. In addition to the total case requirements, the ACGME establishes defined category minimums for operative experiences which must be met prior to the completion of training.

\section{Evaluation}

The process and requirements of trainee evaluation is further defined in the General Surgery Program Requirements through the ACGME Surgery Milestones. As discussed in the Common Program Requirements, a General Surgery Clinical Competency Committee is responsible for the assessment of a trainee's progress in each of the ACGME core competencies. The Surgery Milestones is a framework designed for the evaluation of surgical trainees in each of these competencies. The Surgery Milestones are arranged into levels from Level 1 (novice) to Level 5 (expert) and are accompanied by specific examples to help guide the appropriate assessment of performance. The Milestones are performed semi-annually and should illustrate the progression of a learner's performance and abilities over time.

\section{Program Accreditation and Review Process}

Accredited surgical programs must comply with the ACGME Common and Surgery Program Requirements. Accreditation is overseen by the Residency Review Committee (RRC) which reviews programs on an annual basis. Programs report to the RRC through a web-based portal called the Accreditation Data Systems (ADS). Each program must upload an annual report specifying any major changes to the program and responses to previous citations for areas of non-compliance. In addition to the annual ADS report, the RRC reviews the graduating resident case logs for adequacy in volume and defined category minimums, and faculty and resident survey results. Based on this information, the RRC decides whether to grant accreditation, give or resolve citations, place a program on probationary status, or pursue further information via an in-person site visit. This process is repeated annually [6].

\section{Sponsoring Institutions}

In addition to training program accreditation, the ACGME confers institutional accreditation. As mentioned previously, programs applying for accreditation must have an ACGME accredited sponsoring institution. In order to obtain institutional accreditation, an institution must apply and comply with the ACGME Institutional Requirements.

\section{Institutional Requirements}

The ACGME Institutional Requirements set the standards for sponsoring institutions in four main areas: structure for educational oversight, institutional resources, the learning and working environment, and institutional GME policies and procedures. These key elements are illustrated in Table 2, and briefly described below [7].

\section{Structure for Educational Oversight}

The overall structure and educational oversight of the sponsoring institution requires a Designated Institutional Official (DIO) and a Graduate Medical Education Committee

Table 2 ACGME Institutional Requirements

\begin{tabular}{ll}
\hline Sponsoring Institutional Requirement & Description \\
\hline $\begin{array}{l}\text { Structure for Educational Oversight } \\
\text { Institutional Resources }\end{array}$ & $\begin{array}{l}\text { Establishes the Designated Institutional Official (DIO) and the Graduate Medical Education } \\
\text { Committee (GMEC) and requirement for effective governance of all training programs in the } \\
\text { institution } \\
\text { Adequate financial and non-financial resources must be present to prevent excessive reliance on } \\
\text { trainees }\end{array}$ \\
$\begin{array}{l}\text { The Learning and Working Environment } \\
\text { Sets standards for patient safety, quality improvement, and the learning and work environment }\end{array}$ & \begin{tabular}{l} 
Establishes policies and procedures to ensure transparent and equitable treatment of trainees \\
\hline
\end{tabular}
\end{tabular}


(GMEC). The DIO is the individual with authority and oversight over all programs for the sponsoring institution. In addition to compliance with the Institutional Requirements, the DIO must also ensure that each program is in compliance with the Common Program and Specialty Specific Program Requirements. The DIO works in collaboration with the GMEC to help attain and maintain compliance of all sponsored programs. The GMEC is the governing body which is usually comprised of residency and fellowship Program Directors. The DIO and GMEC must demonstrate effective oversight over all training programs for the sponsoring institution.

\section{Institutional Resources}

All sponsoring institutions must have adequate financial and non-financial resources to support the DIO, program administration, faculty, trainees, and patients. The financial resources are in the form of protected time, salaries, and benefits. In addition, sponsoring institutions must have adequate support services and systems to provide patient care without excessive reliance upon trainees. Examples of these support systems include ancillary services and patient transportation. Finally, sponsoring institutions must also provide adequate communication tools and educational resources to ensure adequate communication and access to medical literature for the providers and trainees.

\section{The Learning and Working Environment}

The learning and working environment established by the Common Program Requirements and the Specialty Program Requirements are also required of the sponsoring institution. Standards of patient safety, quality improvement, transitions of care, supervision and accountability, education, professionalism, and well-being are required at the sponsoring institutional level in order to establish a culture of safety for all underlying programs. This requirement aligns the overall institutional environment with those of its individual programs.

\section{Institutional GME Policies and Procedures}

The sponsoring institution must have a set of formal policies and procedures that have been approved by the DIO and GMEC that governs the treatment of trainees. These policies include the areas of resident and fellow appointment, renewal, promotion, dismissal, disability, leave, grievances, and supervision. These policies and procedures ensure the transparent and equitable treatment of trainees in all programs within the sponsoring institution.

\section{Institutional Accreditation and Review Process}

Similar to ACGME Program Accreditation, the accreditation of sponsoring institutions is voluntary. Institutional accreditation is overseen by the Institutional Review Committee and based upon the sponsoring institution's compliance with the ACGME Institutional Requirements. Institutional accreditation is not dependent upon Program accreditation; however, Program accreditation is dependent on accreditation of the sponsoring institution [8].

\section{Clinical Learning Environment Review}

The Clinical Learning Environment Review (CLER) process occurs in parallel to the institutional accreditation process. The CLER process focuses on the resident and fellow learning environment within the institution and is designed to provide feedback in six specific areas: patient safety, health care quality, care transitions, supervision, well-being, and professionalism. The feedback is provided in order to help improve engagement of clinical trainees in safe high-quality patient care. Although the CLER process occurs independently of the accreditation review process by the Institutional Review Committee, it is required every two years in order to maintain accreditation [9].

\section{How Is an Individual Surgeon Certified for Independent Practice in the USA?}

Trainees who complete an ACGME accredited program in an ACGME accredited institution are not board certified by the ACGME. The responsibility for assessment and certification of individual surgeons and physicians is held by the American Board of Medical Specialties (ABMS) and its 24 Member Boards. This two-party system ensures that the graduates of the training programs meet objective criteria for surgical knowledge and judgment by surgeons or physicians who did not participate in their training and that objective measures of capability are met. The mission of the ABMS is "to serve the public and the medical profession by improving the quality of health care through setting professional standards for lifelong certification in partnership with Member Boards" [10]. Individuals seeking board certification must meet the training requirements and successfully complete the board examination process established by their specialty's Member Board. For example, surgeons who have completed their ACGME accredited training program in general surgery seek board certification through the American Board of Surgery. 


\section{The American Board of Surgery}

The American Board of Surgery is one of the 24 Member Boards of the ABMS and was founded in 1937. The American Board of Surgery (ABS) is an independent nonprofit organization that serves the public by establishing excellence through rigorous initial examination and continued examination for initial and continuous certification of practicing surgeons. ABS board certification is a voluntary process but can be required or sought after by employers and patients. Most, but not all, hospitals in the USA require ABS certification as a criterion for holding surgical privileges at the institution. The ABS offer board certification in General Surgery, Vascular Surgery, Surgical Oncology, Pediatric Surgery, Plastic Surgery, Hand Surgery, and Surgical Critical Care. Currently, there are approximately 31,000 ABS board certified surgeons [11].

The ABS is led by a board of directors which is comprised of surgeons who are engaged in surgical training and who are nominated by the leading surgical organizations in the USA; the ABS also has a non-surgeon community director and three at-large directors elected through an open nomination process. The members of the board of directors are not compensated and allow the ABS to achieve its purpose to conduct examinations, issue certificates, and improve graduate education and training opportunities for surgeons [11].

The initial board certification process in General Surgery requires fulfillment of training requirements and successful performance on two examinations, the qualifying exam and the certifying exam. The training requirements must be fulfilled to be eligible to take the qualifying examination. All training following medical school must be completed at an ACGME accredited program or a Royal College of Physicians and Surgeons of Canada (RCPSC) accredited program. Osteopathic General Surgery training programs accredited by the ACGME also meet this requirement. In addition to completion of training at an accredited program, the Program Director must attest to the knowledge, skill, judgment, and ethics of the applicant. The qualifying exam is a written multiple-choice examination that must be taken within seven years of completion of the accredited training program. Once an applicant has passed the qualifying examination they are eligible to take the certifying examination. The certifying examination is an oral examination and the final step to successful board certification. An ABS certified surgeon is identified as a diplomate, and becomes eligible for application for Fellowship in the American College of Surgeons [12].

Continuous certification by the ABS is a post-initial board certification program that assesses of ongoing knowledge and focuses on contemporary developments in surgical practice with the goal of keeping diplomates up to date.
Diplomates seeking ongoing certification must enroll in this process which involves continuous medical education (CME) credit requirements and an interactive online open book examination every two years. The examination is a mix of core and practice related questions in a chosen area. The examination provides instantaneous feedback and is accompanied by resources to aid in acquisition of up to date knowledge and practice guidelines [13].

\section{The Role of Surgical Professional Societies}

Professional surgical societies play an important role in the implementation of the frameworks required by the ACGME. These societies, most notably the American College of Surgeons through many programs and offerings, provide courses and educational content for surgical education and training to serve a surgeon throughout lifelong learning and retooling, while also providing contributions to surgical education policy and advancement. While in recent years, the list of surgical societies has grown and many other surgical organizations have contributed to both surgical education, training and verification of training programs in the USA, we will highlight the work of several of the societies and review their role in strengthening the surgical workforce.

\section{The American College of Surgeons}

The American College of Surgeons (ACS) is a scientific and educational association of surgeons that was founded in 1913 to improve the quality of care for the surgical patient by setting high standards for surgical education and practice [14]. The mission of the ACS is to be "dedicated to improving the care of the surgical patient and to safeguarding standards of care in an optimal and ethical practice environment." Comprised of more than 82,000 members, including nearly 7000 in other countries, the ACS is the largest organization of surgeons in the world. Members of the ACS are referred to as Fellows. The letters FACS after a surgeon's name mean that the surgeon's education and training, professional qualifications, surgical competence, and ethical conduct have passed a rigorous evaluation and are consistent with the ACS high standards. (4a) In the USA, the American College of Surgeons holds special status as the convener of all other surgical professional societies and regulatory agencies to address current and future needs of the surgical profession across all domains in surgery.

\section{ACS Division of Education}

Commitment to education has always been at the forefront of the mission of the ACS. The ACS Division of Education has created many programs to support the professional 
development of surgeons and surgical educators and policy makers at all career levels [15]. See Table 3 for a list of some of the key division program courses and resources.

\section{Academy of Master Surgeon Educators}

The Academy of Master Surgeon Educators was established in 2018 by the ACS Division of Education [16]. The mission of the academy is to take a leadership role in advancing the science and practice of surgical education across all specialties. Since inception, members of the Academy have contributed to advancing surgical education even during the COVID19 pandemic. In 2019, the Academy hosted a special Symposium on Emerging Technologies and Artificial Intelligence in Surgical Care and Education. In 2020, during the early stages of the COVID-19 pandemic, a Special Committee to Address Challenges and Opportunities Relating to Surgery Residency Training During the COVID-19 Pandemic was appointed.

\section{The Association of Program Directors in Surgery}

The Association of Program Directors in Surgery was established in the 1977 and is the primary convening home for surgical program directors and surgical educators focused on surgical graduate medical education. The main goals of the organization are to (1) maintain high standards of surgical residency training by improving graduate surgical education and patient care, (2) provide advice, assistance, and support to program directors on matter pertaining to surgical education and accreditation, and (3) represent the interests program directors in education and training of high-quality surgeons to other organizations, individuals, governmental agencies, or regulatory bodies [17].

\section{The Association for Surgical Education}

The Association for Surgical Education was formed in 1980 and its members represent over 190 medical schools and institutions throughout the USA. With a focus on educational scholarship, the mission of the Association for Surgical Education (ASE) is to lead innovation, scholarship, and professional development in surgical education. ASE has two fellowship opportunities that align with their mission, the Surgical Education and Leadership Fellowship (SELF) and the Surgical Education Research Fellowship (SERF) $[18,19]$. SELF is a one-year fellowship designed for all ASE members to improve their teaching, education design, and leadership skills in surgical education. SERF is a one year, home-site fellowship designed to equip investigators with the skills and knowledge needed to plan, implement, and report research studies in the field of surgical education.

\section{The American Surgical Association}

Established in 1880, the American Surgical Association is the oldest academic surgical association in the USA; its limited membership is comprised of academic leaders from across the nation, many of whom direct departments and faculty who train the future surgical workforce. The primary mission of the American Surgical Association (ASA) is to be the premier organization for surgical science and scholarship and to provide a national forum for presenting the developing state of the art and science of general and sub-specialty surgery and the elevation of the standards of the medical/surgical profession [20]. In 2002, recognizing the multitude of changes taking place in surgical technology and patient care, the ASA Council in partnership with the American College of Surgeons (ACS), the American Board of Surgery (ABS), and RRC established a Blue-Ribbon Committee on Surgical Education. The Committee was charged with examining

Table 3 ACS Division of Education available courses and resources

\begin{tabular}{|c|c|}
\hline ACS Division of Education course/resource offerings & Description \\
\hline ACS Surgeons as Educators & $\begin{array}{l}\text { Six-day course intended for full time faculty members interested in honing } \\
\text { skills in curriculum development, teaching, and performance and program } \\
\text { evaluation }\end{array}$ \\
\hline ACS Surgeons as Leaders: From Operating Room to Boardroom & $\begin{array}{l}\text { Three-day course for surgeons who currently serve in leadership positions } \\
\text { who seek to enhance their leadership skills across a wide variety of settings }\end{array}$ \\
\hline ACS Residents as Teachers and Leaders & $\begin{array}{l}\text { Three-day course for residents designed to help them develop essential non- } \\
\text { clinical skills in teaching and leadership that will be critical to their success } \\
\text { as senior level residents and practicing surgeons }\end{array}$ \\
\hline ACS Entering Resident Readiness Assessment (ACS ERRA) & $\begin{array}{l}\text { Online, case-based instrument to measure the preparedness of entering surgi- } \\
\text { cal residents. The assessment focuses on clinical decisional making with } \\
\text { scenarios that may be encountered at the beginning of residency. Results can } \\
\text { be used to identify resident strengths and develop learning plans }\end{array}$ \\
\hline Ethical Issues in Surgical Care & $\begin{array}{l}\text { Textbook that defines the field of surgical ethics and provides a foundation for } \\
\text { understanding central ethical issues in a surgical practice }\end{array}$ \\
\hline
\end{tabular}


the multitude of forces impacting health care and making recommendations regarding the changes needed in surgical education to serve all the surgical needs of the nation, and to keep training and research in surgery at the cutting edge in the twenty-first century [21]. This report emphasized the need for surgical training to be tailored to the needs of specific disease profiles and to incorporate new technologies in order to compensate for the decreased patient exposure encountered in the training of the modern surgeon. Additionally, the committee made several recommendations regarding surgical residency structure, suggesting a focus on maximizing efficiency, diminishing training duration with an increased focus on education rather than hospital service needs. Many of these concepts and practices have been implemented into surgical training paradigms over the last two decades.

\section{Surgical Council on Resident Education}

The Surgical Council on Resident Education (SCORE) is a nonprofit, noncommercial consortium that was organized in 2004. SCORE's mission is to improve the education of trainees in general surgery and related specialties through the development of a national curriculum [22]. The online SCORE Portal was created to provide high-quality curriculum paired educational content developed by surgical educators and reviewed by the SCORE Editorial Board.

Content is developed in accordance with the six competencies required of a graduating resident: patient care, medical knowledge, professionalism, interpersonal and communication skills, practice-based learning, and systems-based practice. See Table 4 for a list of the organizational members of who help guide SCORE's mission.

\section{Evolving Focus Areas in US Surgical Training}

Despite the standards for training program accreditation and individual board certification, the ACGME, ABS, ACS, and multiple surgical professional societies have identified gaps in training and areas requiring focus in surgical education.

Table 4 SCORE organizational members

\begin{tabular}{l}
\hline Organizing SCORE members \\
\hline American Board of Surgery \\
American College of Surgeons \\
American Surgical Association \\
Association of Program Directors in Surgery \\
Association of Surgical Education \\
Residency Review Committee for Surgery \\
Society of American Gastrointestinal and Endoscopic Surgeons
\end{tabular}

These focus areas have gained much attention, research, and investment in the academic surgical community and serve as priorities for the near future.

\section{The Learning Environment}

The learning environment is an essential aspect of surgical training that encompasses the expectations, perceptions, and educational culture of the trainee and faculty. The importance of the learning environment has become increasingly apparent both at the medical student and resident level. Misaligned expectations, mistreatment, and curricular inconsistencies have been identified as factors contributing to a poor educational environment [23]. As surgical education continues to evolve with entry of young residents with different generational qualities and goals who are also more diverse in many traits, innovative teaching methods and the imperative to create a positive learning environment is now recognized to be essential to optimizing learning and professional development of young surgeons.

\section{Diversity and Inclusion}

A diverse and inclusive surgical workforce is critical to physician health and well-being and is linked to patient outcomes as we strive to reduce unacceptable health disparities based on race and socioeconomic status [24, 25]. During the COVID19 pandemic, the disproportionate use of lethal force in the Black community firmly placed issues of social justice and systemic racism in the forefront of social and political commentary. These discussions also placed a very needed spotlight on diversity, equity, inclusion, and systemic racism in our healthcare systems. In response, all of the professional societies highlighted in this manuscript and many surgical departments across the country released statements and action plans to develop programs that focus on antiracism in medicine. Current events have also allowed smaller professional societies such as The Society of Black Academic Surgeons, The Latino Surgical Society, the Society of Asian Academic Surgeons, and the Association of Women Surgeons to have much needed elevated platforms and influence as the profession develops divisions, task forces, and curriculums focused on diversity, equity, and inclusion. While there is much work to be done, we are encouraged by these recent efforts and believe that continued intentional focus in this area will move us towards a truly diverse, equitable, and inclusive surgical workforce.

\section{Resident Satisfaction}

Physician wellness and avoidance of burnout is an area of critical importance as the incidence of physician burnout and mistreatment of trainees is alarmingly high [26]. Surgeons are 
having more difficulty in achieving work-life balance despite the work-hour regulations established by the ACGME. Surgeon wellness and burnout has effects extending beyond the individual and has significant ramifications on patients, colleagues, and the entire work environment. The Surgical Education Culture Optimization through targeted interventions based on National comparative Data (SECOND) Trial is a current randomized trial performed in conjunction with multiple surgical societies including the ACGME, ABS, and ACS. In this trial, training programs are provided with their performance data on wellness and burnout compared to peer programs. This study then randomizes programs into an intervention arm where a wellness toolkit and implementation support are provided, and a control arm with no intervention [27]. The SECOND Trial is ongoing and illustrates the importance of wellness even prior to the Coronavirus Pandemic. The Coronavirus Pandemic has further illustrated the need for progress in this area.

\section{Entrustable Professional Activities}

The transition to competency based medical education is rooted in the ACGME Core Competencies. Although the ACGME defines these six core competencies, the implementation in medical education is challenging. Entrustable Professional Activities are a technique used to implement competency-based medical education. Entrustable Professional Activities (EPAs) provide a graduated approach to a specific clinical activity which begins with performance under direct supervision and through levels of entrustability concludes with independent practice and autonomy. EPAs have been successfully integrated into surgical training programs and are an important tool in competency based medical education [28].

\section{Faculty Development}

Teaching faculty are critical to the success of surgical residency programs. In addition to faculty development courses/ programs by professional societies, most notably those of the American College of Surgeons and the Association for Surgical Education in recent years, many institutions and surgical departments have created faculty development programs and centers for faculty development to promote faculty career development at their home institutions. These centers aim to support faculty in delivering innovative teaching and learning experiences, advancing education practice, and growing as educational leaders locally and nationally.

\section{Conclusion}

The structure of surgical training in the USA has evolved significantly from the classic apprenticeship model. While rooted in the Halstedian training model, current US surgical training involves a complex but beneficial relationship between accrediting bodies and surgical societies creating an educational landscape with clear standards and an environment that supports collaboration and advancement of surgical education.

Author Contribution All authors contributed to the study conception and design. Material preparation, data collection, and analysis were performed by all authors. The first draft of the manuscript was written by all authors. All authors read and approved the final manuscript.

\section{Declarations}

Conflict of Interest The authors declare no competing interests.

\section{References}

1. Are C (2016) Workforce needs and demands in surgery. Surg Clinics 96(1):95-113

2. ACGME (2021) ACGME About Us [Internet]. ACGME. [cited 2021Jun25]. Available from: https://acgme.org/About-Us/Overv iew/

3. ACGME (2021) What We Do [Internet]. ACGME. [cited 2021Jun25]. Available from: https://acgme.org/What-We-Do/ Overview/

4. ACGME (2020) [Internet]. ACGME Common Program Requirements. ACGME; [cited 2021Jun24]. Available from: https:// acgme.org/Portals/0/PFAssets/ProgramRequirements/CPRRe sidency2020.pdf

5. ACGME (2020) ACGME Program Requirements for Graduate Medical Education in General Surgery [Internet]. Program Requirements in General Surgery. ACGME; [cited 2021Jun24]. Available from: https://acgme.org/Portals/0/PFAss ets/ProgramRequirements/440_GeneralSurgery_2020.pdf?ver= 2020-06-22-085958-260

6. ACGME (2021) Accreditation [Internet]. ACGME. [cited 2021Jun25]. Available from: https://acgme.org/What-We-Do/ Accreditation/

7. ABMS (2021) About ABMS [Internet]. American Board of Medical Specialties. [cited 2021Jun25]. Available from: https://www. abms.org/about-abms/

8. ACGME (2018) [Internet]. ACGME Institutional Requirements. ACGME; [cited 2021Jun24]. Available from: https://acgme.org/ Portals/0/PFAssets/InstitutionalRequirements/000Institutiona 1Requirements2018.pdf?ver=2018-02-19-132236-600

9. ACGME (2021) Institutional Review Committee [Internet]. ACGME. [cited 2021Jun25]. Available from: https://acgme.org/ Designated-Institutional-Officials/Institutional-Review-Commi ttee/

10. ACGME (2021) Clinical Learning Environment Review (CLER) [Internet]. Clinical Learning Environment Review. ACGME; [cited 2021Jun25]. Available from: https://acgme.org/What-WeDo/Initiatives/Clinical-Learning-Environment-Review-CLER/ 
11. ABS (2021) About Us [Internet]. American Board of Surgery. [cited 2021Jun25]. Available from: https://www.absurgery.org/ default.jsp?abouthome

12. ABS (2021) Continuous Certification [Internet]. American Board of Surgery. [cited 2021Jun25]. Available from: https://www.absur gery.org/default.jsp?exam-moc

13. ABS (2021) Becoming Certified [Internet]. American Board of Surgery. [cited 2021Jun25]. Available from: https://www.absur gery.org/default.jsp?examoffered

14. ACS (2021) About ACS [Internet]. [cited 2021Jul14]. Available from: https://www.facs.org/about-acs

15. ACS Division of Education (2021) About the ACS Division of Education [Internet]. [cited 2021Jul14]. Available from: https:// www.facs.org/education/division-of-education

16. Academy of Master Surgeon Educators (2021) About the Academy of Master Surgeon Educators [Internet]. [cited 2021Jul14]. Available from: https://www.facs.org/education/academy

17. Association of Program Directors in Surgery (2021) About the Association of Program Directors in Surgery [Internet]. [cited 2021Jul14] Available from: https://apds.org/about/

18. Surgical Education and Leadership Fellowship (2021) About SELF [Internet]. [cited 2021Jul14] Available from: https://www. surgicaleducation.com/self/

19. Surgical Education and Research Fellowship (2021) About SERF [Internet]. [cited 2021Jul14] Available from: https://www.surgi caleducation.com/surgical-education-research-fellowship-overv iew/

20. ASA (2021) About American Surgical Association. [Internet]. [cited 2021Jul14] Available from: https://americansurgical.org/ about.cgi

21. Debas HT, Bass BL, Brennan MF, Flynn TC, Folse JR, Freischlag JA, Friedmann P, Greenfield LJ, Jones RS, Lewis FR Jr, Malangoni MA (2005) American surgical association blue ribbon committee report on surgical education: 2004. Ann Surg 241(1):1
22. SCORE (2021) About the Surgical Council on Resident Education. [Internet] [cited 2021Jul14] Available from: https://www. surgicalcore.org/public/about

23 Castillo-Angeles M, Calvillo-Ortiz R, Barrows C, Chaikof EL, Kent TS (2020) The learning environment in surgery clerkship: what are faculty perceptions? J Surg Educ. 77(1):61-68. https:// doi.org/10.1016/j.jsurg.2019.07.003

24. Mateo CM, Williams DR (2021) Racism: a fundamental driver of racial disparities in health-care quality. Nat Rev Dis Primers $7(1): 1-2$

25. Paradies Y, Ben J, Denson N, Elias A, Priest N, Pieterse A, Gupta A, Kelaher M, Gee G (2015) Racism as a determinant of health: a systematic review and meta-analysis. PloS one 10(9):e0138511

26. Hu YY, Ellis RJ, Hewitt DB, Yang AD, Cheung EO, Moskowitz JT, Potts JR 3rd, Buyske J, Hoyt DB, Nasca TJ, Bilimoria KY (2019) Discrimination, abuse, harassment, and burnout in surgical residency training. N Engl J Med 381(18):1741-1752. https://doi. org/10.1056/NEJMsa1903759

27. The SECOND Trial. The SECOND Trial [Internet] (2020) the SECOND trial - Home Page. [cited 2021Jun25]. Available from: http://www.thesecondtrial.org/

28. Stahl CC, Collins E, Jung SA, Rosser AA, Kraut AS, Schnapp BH, Westergaard M, Hamedani AG, Minter RM, Greenberg JA (2020) Implementation of entrustable professional activities into a general surgery residency. J Surg Educ 77(4):739-748. https:// doi.org/10.1016/j.jsurg.2020.01.012

Publisher's Note Springer Nature remains neutral with regard to jurisdictional claims in published maps and institutional affiliations. 